\title{
Study on Mechanical Properties and Components of HRB400 Steel for High-strength Building
}

\author{
Jingrong $\mathrm{WU}^{1, \mathrm{a}}$ and yongsheng $\mathrm{LI}^{2, \mathrm{~b}}$ \\ ${ }^{1}$ Hubei University of Technology Engineering and Technology College, China \\ ${ }^{2}$ Hubei University of Technology Engineering and Technology College, China \\ a964877562@qq.com,b809607948@qq.com
}

\begin{abstract}
The study took five samples of screw-thread steel III, i.e. HRB400 steel bar of different diameters: $10 \mathrm{~mm}, 12 \mathrm{~mm}, 16 \mathrm{~mm}, 20 \mathrm{~mm}$ and $25 \mathrm{~mm}$; and conducted contrast experiments of their mechanical properties and components. The 600 sets of data collected from the experiments were processed by multivariate regression analysis of mechanical properties and components by diameter with MATLAB. The result showed that differentHRB400 screw-thread steel bars have different components with the mechanical properties meeting the standard of GB1499.2-2007 ${ }^{[1]}$ part 2 steel for reinforced concrete hot rolled ribbed steel bar, which has a guidance function to scientific research in universities and production in enterprises.
\end{abstract}

\section{Introduction}

With the accelerated urbanization process of our country, building steel becomes an important guarantee of structure safety. The main high-tensile steel bar used in our country is HRB400 steel. The HRB400 steel bar is one kind of screw-thread steel III and hot rolled ribbed steel bar. HRB400 screw-thread steel is high-tensile aseismic steel which has good extension, with a price higher than screw-thread steel I, II. At present, with intensive national infrastructure, our country are promoting high-tensile aseismic steel. Meanwhile, there are longitudinal ribs and transverse ribs on the surface of screw-thread steel, with enhanced adhesive force to concrete usually by two transverse ribs and longitudinal ribs evenly distributed lengthwise, which widely used in building projects of houses, bridges, roads and railways ${ }^{[2,4]}$. After reverse bend test, the bending part of screw-thread steel can avoid cracks on the surface. There is a strong relationship between the mechanical properties of HRB400 steel bar (yield points, strength of extension and extensibility) and its components (carbon, manganese, phosphorus, sulfur, oxygen, silicon and nitrogen). Components decide the mechanical properties of steel. Different components have different mechanical properties. Therefore. On condition that the mechanical properties meet the standard of GB1499.2-2007 ${ }^{[1]}$ part 2 steel for reinforced concrete hot rolled ribbed steel bar,

\footnotetext{
*Corresponding author: 864877562@qq.com
} 
the study analyzed the components of HRB400 screw-thread steel of different diameters. The HRB400 screw-thread steel in the study is the hot charging minus deviation bars bought by school.

\section{Equipment}

Drawing equipment: steel extension tester WEW-600 ofmicrocomputer-based panel made by Jinan Huaxin Company; Chemical analysis: photoelectric direct-reading spectrographof Germany SPECTRO; Mathematical statistics: Lenovo PC and multivariate regression analysis with MATLAB.

\section{Process}

The experiment conducted check experiment of the mechanical properties and components of the HRB400 steel bars $(10 \mathrm{~mm}, 12 \mathrm{~mm}, 16 \mathrm{~mm}, 20 \mathrm{~mm}$ and $25 \mathrm{~mm})$ bought for this experiment. And these five specifications are comparative test analyzed their Mechanical Properties and one by one and 600 sets got from the experiments were input in the computer separately in order to multiple linear regression analyze their mechanical properties $\left(\sigma_{\mathrm{b}} 、 \sigma_{\mathrm{s}}\right)$ and chemical composition (carbon $(\mathrm{C})$, silicon $(\mathrm{Si})$, manganese $(\mathrm{Mn})$ ). There are 100 sets experiments for the $10 \mathrm{~mm}$ bars, 114 sets for the $12 \mathrm{~mm}$ bars, 113 sets for the $16 \mathrm{~mm}$ ones, 125 sets for the $20 \mathrm{~mm}$ ones, 148 sets for the $25 \mathrm{~mm}$ ones.

\section{Results and Analysis}

Results of calculating the data of mechanical property and component, see in Table 1:

Table 1: Hrb400mechanical Property\&Component

\begin{tabular}{|l|l|l|l|l|l|}
\hline Size[diamet & $\sigma_{\mathrm{b}} / \mathrm{Mpa}$ & $\sigma_{\mathrm{s}} / \mathrm{Mpa}$ & $\mathrm{C} / \%$ & $\mathrm{Si} / \%$ & $\mathrm{Mn} / \%$ \\
\hline $\mathrm{er}]$ & & & & & \\
\hline $10 \mathrm{~mm}$ & 564.72 & 366.78 & 0.1973 & 0.5903 & 1.3466 \\
\hline $12 \mathrm{~mm}$ & 572.87 & 376.67 & 0.2017 & 0.6001 & 1.3560 \\
\hline $16 \mathrm{~mm}$ & 559.84 & 369.23 & 0.1910 & 0.5811 & 1.3378 \\
\hline $20 \mathrm{~mm}$ & $551.31 \mathrm{~s}$ & 358.95 & 0.1989 & 0.5764 & 1.3497 \\
\hline $25 \mathrm{~mm}$ & 540.56 & 360.37 & 0.1879 & 0.5865 & 1.3491 \\
\hline
\end{tabular}

Diameter 10mm Size (100sets)Regression equation:

$\sigma_{b}=310.2893+295.3874 \mathrm{C}+23.2893 \mathrm{Si}+128.3834 \mathrm{Mn} \quad \mathrm{R}=0.6833$

$$
\sigma_{\mathrm{s}}=278.3938+384.3838 \mathrm{C}+59.6747 \mathrm{Si}+12.3485 \mathrm{Mn} \quad \mathrm{R}=0.6748
$$

Diameter $12 \mathrm{~mm}$ Size (114 sets) Regression equation: 
$\sigma_{b}=369.2937+276.1093 \mathrm{C}+20.1937 \mathrm{Si}+142.3874 \mathrm{Mn} \quad \mathrm{R}=0.6989$

$$
\sigma_{\mathrm{s}}=282.2749+339.0193 \mathrm{C}+45.3837 \mathrm{Si}+19.3003 \mathrm{Mn} \quad \mathrm{R}=0.6642
$$

Diameter 16mm Size (113sets) Regression equation:

$\sigma_{b}=274.9378+283.9409 \mathrm{C}+75.9403 \mathrm{Si}+80.4039 \mathrm{Mn} \quad \mathrm{R}=0.8102$

$$
\sigma_{\mathrm{s}}=158.9056+389.9084 \mathrm{C}+66.3029 \mathrm{Si}+78.3094 \mathrm{Mn} \quad \mathrm{R}=0.7348
$$

Diameter 20mm Size (125 sets) Regression equation:

$$
\begin{aligned}
& \sigma_{b}=229.4393+448.9385 \mathrm{C}+57.3938 \mathrm{Si}+164.9380 \mathrm{Mn} \quad \mathrm{R}=0.6669 \\
& \sigma_{\mathrm{s}}=139.2933+261.3029 \mathrm{C}+87.9302 \mathrm{Si}+69.3872 \mathrm{Mn} \quad \mathrm{R}=0.6143
\end{aligned}
$$

Diameter 25mm Size (148 sets) Regression equation:

$$
\begin{aligned}
& \sigma_{b}=285.4394+830.3048 \mathrm{C}+31.4873 \mathrm{Si}+69.3937 \mathrm{Mn} \quad \mathrm{R}=0.7803 \\
& \sigma_{\mathrm{s}}=241.3984+264.2927 \mathrm{C}+57.2937 \mathrm{Si}+31.3098 \mathrm{Mn} \quad \mathrm{R}=0.6472
\end{aligned}
$$

With current resources and teaching conditions of the school, the experimenter concluded that the above equations of different diameters are credible after collecting mass data to verify them and communicating with experienced teachers and students.

According to the standard of GB1499.2-2007 $7^{[1]}$ part 2 steel for reinforced concrete hot rolled ribbed steel bar, the maximum of $\mathrm{C}, \mathrm{Si}$, and $\mathrm{Mn}$ in HRB400 steel are $0.25 \%, 0.80 \%$ and $1.60 \%$; the maximum of $C_{e q}$ are $0.52 \%, 0.54 \%$ and $0.55 \%$, without lower limits. Therefore, to increase benefits and decrease costs and the content of alloy elements in projects, the mechanical properties of HRB400 steel of different diameters show great difference on condition that the mechanical properties meet the standard of GB1499.2-2007 $7^{[1]}$ part 2 steel for reinforced concrete hot rolled ribbed steel bar. See the mechanical properties of two sets of components (theoretical calculation) in Table 2:

Table 2: Mechanical Property\& Component

\begin{tabular}{|c|c|c|c|c|c|c|c|c|}
\hline \multicolumn{3}{|c|}{ Component \% } & & \multicolumn{5}{|c|}{ Mechanical Property /MPa } \\
\hline $\mathrm{C}$ & $\mathrm{Si}$ & $\mathrm{Mn}$ & & $10 \mathrm{~mm}$ & $12 \mathrm{~mm}$ & $16 \mathrm{~mm}$ & $20 \mathrm{~mm}$ & $25 \mathrm{~mm}$ \\
\hline \multirow{2}{*}{0.18} & \multirow{2}{*}{0.41} & \multirow{2}{*}{1.20} & $\sigma_{\mathrm{b}}$ & 534.89 & 508.23 & 521.30 & 518.39 & 497.93 \\
\cline { 4 - 9 } & & & $\sigma_{\mathrm{s}}$ & 370.49 & 364.90 & 343.23 & 342.83 & 318.49 \\
\hline \multirow{2}{*}{0.29} & \multirow{2}{*}{0.60} & \multirow{2}{*}{1.40} & $\sigma_{\mathrm{b}}$ & 573.98 & 564.30 & 539.72 & 572.74 & 560.23 \\
\cline { 4 - 9 } & & & $\sigma_{\mathrm{s}}$ & 397.39 & 389.49 & 388.93 & 370.19 & 354.22 \\
\hline
\end{tabular}


HRB400 steel belongs to the hypo eutectoid steel, which is small section steel and mainly used for the skeleton of the steel reinforced concrete structure, and its matrix microstructure is ferrite and pearlite. The relative content of ferrite and pearlite and their microstructure, distribution and grain size will directly affect the mechanical properties of steel. The higher the content of ferrite, the higher the plasticity and toughness of the steel bar, but its strength and hardness will be reduced, and vice versa. The higher the pearlite content, the higher the strength of the steel, and vice versa. Under the premise of the chemical composition, the internal structure of the steel directly affects the mechanical properties. At the same time, the shape of the steel is changed during rolling process, and the internal structure of the reinforcing bar is changed by processing hardening, crystallization, recovery and other organizational changes, and finally the mechanical properties of steel is determined. Based on these theoretical knowledge, the alloy element content of small size steel should be low, the alloy element content of large size steel should be high. One of the reasons is the compression ratio of rolling: small-diameter steel bars have big compression ratioof rolling and large-diameter steel bars have small compression ratio of rolling ${ }^{[4]}$. Bigger compression ratio of rolling can make steel organized intensive, which therefore increases the mechanical properties. Another reason is the speed of cooling: small-diameter steel bars cool faster, which increases the mechanical properties.

\section{Conclusion}

1. The chemical composition of the steel bars with different diameters, which meet the standard of GB1499.2-2007[1] part 2 steel for reinforced concrete hot rolled ribbed steel bar should be within the limits: the lower limit of C, Si and Mn for the barsof $10 \mathrm{~mm}$, $12 \mathrm{~mm}, 14 \mathrm{~mm}$ and $16 \mathrm{~mm}$ should be $0.18 \%, 0.31 \%$ and $1.20 \%$; the lower limit of $\mathrm{C}$, Si and Mn for the bars of $18 \mathrm{~mm}, 20 \mathrm{~mm}$ and $22 \mathrm{mmhould}$ be $0.19 \%, 0.39 \%$ and $1.25 \%$; and the lower limit of C, Si and Mn for the bars of $18 \mathrm{~mm}, 20 \mathrm{~mm}, 22 \mathrm{~mm}$ should be $0.20 \% 、 0.50 \%$ and $0.40 \%$;

2. It can lower the alloy content of steel, reduce cost and increase benefit by making short-diameter steel bars. When making large-diameter steel bars, the alloy content shall be kept within a certain range. Properly increased alloy content can guarantee the quality of steel.

3. With different components of steel, its toughness, cold bending and fatigue resistance show differences.

4. Increasing the content of $\mathrm{C}$ can increase the strength but lower the performance of welding and cold-bending.

5. Mn can greatly improve the ultimate tensile strength of steel, but lower its extension and performance of welding with higher content.

6. Si can improve the yield strength of steel but increase its cold brittleness and weaken performance of welding.

\section{References}

1. PRC National Standard GB1499.2-2007.

2. Peng Xiaoqin. Building Materials Engineering Experiment. Beijing. China Building Materials Press. 2000.60-62.

3. Wang Mingjun, Liu Xinbin, Li Zhongmin. Study on Mechanical properties and components of 20MnSi Steel. Gold standard and quality. 2000. Issue IV.

4. Wang Zhongde. Building Materials Experiment Manual (second edition). Beijing. China Architecture \& Building Press. 2003. 